\title{
Central Venous Oxygen Saturation as a Surrogate Marker for Outcome in Critically ill Patients-A Prospective Observational Cohort Study
}

\author{
Sandeep Gajbe ${ }^{1}$, Sona Dave ${ }^{1}$ and Rajesh Kasimahanti ${ }^{2 *}$ \\ ${ }^{1}$ Department of Anesthesia, Nair Hospital, India \\ ${ }^{2}$ Department of Critical Care Medicine, Yashoda Hospitals, India
}

Submission: May 21, 2018; Published: May 29, 2018

*Corresponding author: Rajesh Kasimahanti, Department of Critical Care Medicine, Yashoda Hospitals, Secunderabad, Pin: 500003, India, Email: rajeshkasimahanti@gmail.com

\begin{abstract}
Background and Aims: Mixed venous oxygen saturation aids in assessing tissue oxygenation. However considering the invasiveness of the procedure the need to find a surrogate marker. The aim of the study was to observe the measured values of central venous oxygen saturation $\left(\mathrm{ScvO}_{2}\right)$ and their comparison with the outcome as measured by APACHE II score in critically ill patient treated by early goal directed therapy.

Material and Methods: A prospective observational cohort study which included 100 adult patients on prolonged ventilator support ( $>24$ hours) in a tertiary intensive care who received early goal directed therapy were included in the study. Intermittent $\mathrm{ScvO}_{2}$ measurement was compared with the outcome as measured by APACHE II score. APACHE II scoring was done only once on admission of patient.The clinical end point of study was survival or death of patient.

Results and Conclusion: The mean arterial pressure, central venous pressure, $\mathrm{PaO}_{2}$ and urine output were higher amongst the survivors compared to nonsurvivors. The mean $\mathrm{ScvO}_{2}$ in nonsurvivors and survivors was $53.34 \pm 4.08$ and $73.33 \pm 5.03$ respectively. The overall mean day $1 \mathrm{APACHE}$ II score in nonsurvivors and survivors was $24.47 \pm 4.49$ and $11.19 \pm 1$ respectively. In conclusion $\mathrm{ScvO}_{2}$ and day 1 APACHE II score both are highly sensitive and specific measures for predicting mortality in intensive care patients receiving early goal directed therapy. In our study the cut off value for prediction of mortality for day1 APACHE II score was 14 and for $\mathrm{ScvO}_{2}$ it was 63.33 .
\end{abstract}

Keywords: Central venous oxygen saturation; Early goal directed therapy; APACHE II score

\section{Introduction}

Optimization of hemodynamic variables including blood pressure, heart rate, urine output, and central venous pressure are useful end points in the initial treatment of critically ill patients. However global tissue hypoxia may still persist and has been implicated in the development of multiorgan failure. Central venous oxygen saturation $\left(\mathrm{ScvO}_{2}\right)$, which reflects important changes in the $\mathrm{O}_{2}$ delivery/consumption $\left(\mathrm{DO}_{2} / \mathrm{VO}_{2}\right)$ relationship, has been found to be useful in these patients as an early warning sign for tissue hypoxia [1].

Careful monitoring of fluid administration by early goaldirected therapy (EGDT) has been shown to reduce organ failure and hospital stay [2]. This includes maintaining the $\mathrm{ScvO}_{2}$ above $70 \%$ along with 8-12 mmHg central venous pressure (CVP), mean arterial pressure (MAP) above $65 \mathrm{mmHg}$ and urine output above $0.5 \mathrm{ml} / \mathrm{kg} /$ hour [3]. Definitive intensive care unit (ICU) management includes pulmonary artery catheterization and measuring mixed venous oxygen saturation $\left(\mathrm{SvO}_{2}\right)$. The use of pulmonary artery catheter is associated with increased risk. Measurement of $\mathrm{ScvO}_{2}$ using central venous catheter seems to be a simple method for the initial evaluation [4].

Two clinical scenarios in which evidence of clinical utility of $\mathrm{ScvO}_{2}$ has been reported are in early shock resuscitation protocols and in weaning patients from mechanical ventilation [5]. Recent evidence suggests, $\mathrm{ScvO}_{2}$ measurements not only mirror the tissue oxygen delivery but also help in estimating the cardiac output according to the Fick principle and the shunt fraction [6]. APACHE II scoring system is a quantitative indicator of several patient characteristics and helps the clinicians in early diagnosis and initiation of evidence-based protocols for critically ill patients admitted to the ICU [7].

Since APACHE II score is for prediction of outcome and $\mathrm{ScvO}_{2}$ can be surrogate marker for tissue oxygenation which indirectly related to outcome the objectives of our study were to calculate the APACHE II score in critically ill patient on admission, measure 
the $\mathrm{ScvO}_{2}$ in patients receiving EGDT and to correlate the outcome (survival or death) based on $\mathrm{ScvO}_{2}$ and APACHE II score.

\section{Materials and Methods}

This is a prospective observational cohort study conducted on 100 adult patients admitted to the post anesthesia care unit (PACU) or the trauma ward over a period of 1 year (January 2014 to December 2014) of a tertiary care hospital after obtaining approval from institutional ethics committee. Written informed consent was obtained from the patient's relatives. Based on the APACHE II score of $11.34 \pm 6.75$ in the survived and $23.09 \pm 10.01$ in the dead group Gupta et al. [11] the sample size calculation using Med Calc software was 9 per group (dead and survived). However this is a very small size for statistical analysis and since patient enrolment rate was sufficient and all other resources available 100 cases were taken for the present study. Inclusion criteria was patients on prolonged ventilator support $(>24$ hours) who received EGDT at admission. Children, unknown and pregnant patients and those who expired on day 1 of admission were excluded. APACHE II $[7,8]$ (Annexure 1) score on admission was noted. EGDT had been instituted as per ICU protocol which included mechanical ventilation with sedation and/or chemical paralysis and maintaining oxygen saturation up to $95 \%$. Central venous (7.5 G triple lumen catheter and position of tip confirmed on x-ray) and arterial catheterization were performed as a part of the routine ICU management. CVP was maintained at 8 to 12 $\mathrm{mmHg}$ by giving boluses of crystalloid in $500 \mathrm{ml}$. Vasopressors (norepinephrine /dopamine) were added to maintain MAP of $65 \mathrm{mmHg}, \mathrm{ScvO}_{2}$ upto $70 \%$ and an urine output of $0.5 \mathrm{~mL} / \mathrm{kg} /$ hr. Red blood cells were transfused to maintain haematocrit of $30 \%$ (to improve oxygen transport). Blood samples ( $1 \mathrm{ml}$ ) were collected from the central line after discarding the first 3-5 $\mathrm{ml}$ to avoid contamination from flushing solution every 12 hourly and $\mathrm{ScvO}_{2}$ was analyzed (using the Roche OMNT 3286 ABG machine). The clinical end point of study was survival or death of patient. $\mathrm{ScvO}_{2}$ measurement was compared with the outcome (survival or death ) as measured by APACHE II score in patient receiving EGDT Qualitative data was represented in form of frequency and percentage.

\section{Annexures 1}

APACHE II score was a sum of

A. Physiological variables which included rectal temperature, mean arterial pressure $(\mathrm{mmHg})$, heart rate, respiratory rate, FiO2, $\mathrm{pH}$, sodium $(\mathrm{mmol} / \mathrm{L})$, potassium $(\mathrm{mmol} / \mathrm{L})$, creatinine $(\mathrm{mg} / 100$ $\mathrm{ml}$ ), haematocrit (\%), white blood cell count (/mm3), Glasgow Coma Score (GCS) (15-actual GCS);

B. Age: where points were allotted depending on the age of the patient. $45-54$ years $2,55-64$ years $3,65-74$ years $5,>75$ years 6 ; $<44$ years 0 points

C. Chronic Health Points: Non-operative or emergency postoperative +5 points, Elective postoperative +2 points.

Association between qualitative variables was assessed by Chi-Square test with Continuity. Quantitative data was represented using mean \pm Sd and Median \& IQR (Interquartile range). Analysis of Quantitative data between a qualitative variable in nonsurvivors \& survivors was done using unpaired t-test if data passed 'Normality test' and by Mann-Whitney Test if data failed 'Normality test'. Receiver operating characteristic (ROC) curve was plotted for day 1 APACHE II score \& Mean $\mathrm{ScvO}_{2}$ ( $\mathrm{mm} \mathrm{Hg}$ ) by outcome (death) to get cutoff for these two variables. Binary Logistic Regression was performed between Outcome as dependent variable and day 1 APACHE II score as well as Mean $\mathrm{ScvO}_{2}$ (mm Hg) as independent (Predictor) Variables. SPSS Version 17 was used for most analysis and Microsoft Excel 2010 for graphical representation.

\section{Results}

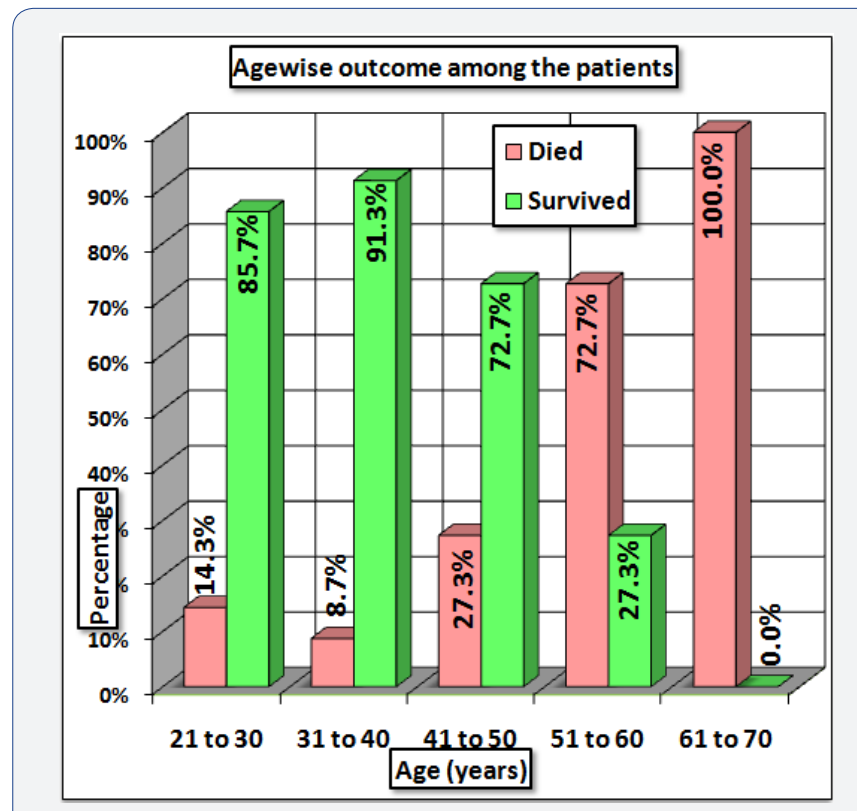

Figure 1: Age wise mortality.

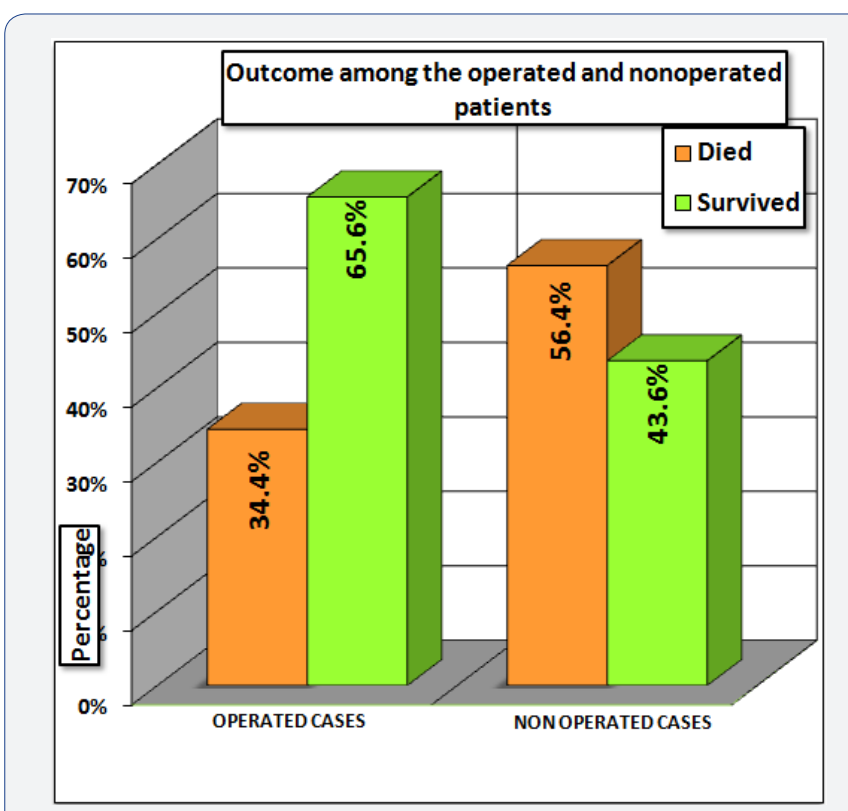

Figure 2: Mortality in Operated and Non operated patients. 
Mortality increased, with increasing age with a $\mathrm{p}$ value (4.95 E-09) being statistically significant (Figure1). The mortality in females and males was $47.7 \%$ and $39.3 \%$ respectively. The mortality was significantly $(\mathrm{P}<0.031$ ) higher in non-operated patients $(56.4 \%)$ compared to that in operated ones $(34.4 \%)$ (Figure 2). The MAP was higher among the survivors (88.03 \pm $2.03 \mathrm{mmHg}$ ) compared to the nonsurvivors $(57.52 \pm 2.26 \mathrm{~mm} \mathrm{Hg})$. The difference was statistically significant (Unpaired t test, $p$ value 5.98E-86). The mean CVP in non survivors was $6.01 \pm 1.71 \mathrm{mmHg}$ and in survivors it was $8.16 \pm 1.27 \mathrm{mmHg}$. The difference was statistically significant (Mann Whitney test, $\mathrm{p}$ value- 7.44E-09).
Thus higher CVP was associated with better chances of survival further favoring early fluid resuscitation.

The mean $\mathrm{PaO}_{2}$ and $\mathrm{PaCO}_{2}$ in survivors was $188.30 \pm 27.97$ $\mathrm{mmHg}$ and $34.79 \pm 2.20 \mathrm{mmHg}$ respectively and in non survivors it was $110.78 \pm 37.23 \mathrm{mmHg}$ and $57.80 \pm 5.50 \mathrm{mmHg}$ and was statistically significant. The mean urine output over a period of 24 hours in nonsurvivors was $435 \pm 115.89 \mathrm{ml}$ compared to $1728 \pm 258.88 \mathrm{ml}$ in survivors with the difference being statistically significant. The mean $\mathrm{ScvO}_{2}$ and day1 APACHE II scores innonsurvivors and survivors are shown in Table $1 \& 2$ respectively.

Table 1: The mean $\mathrm{ScvO}_{2}$ in died patient was $53.34 \pm 4.08$ and the mean $\mathrm{ScvO}_{2}$ in survived patient was $73.33 \pm 5.03$. This differences was statistically significant. (Mann Whitney test, p-value 1.38E-17). Thus the mean $\mathrm{ScvO}_{2}$ was much lower in died patients than in survived patients.

\begin{tabular}{|c|c|c|c|c|c|c|c|}
\hline Variable & Outcome & Mean & Std. deviation & Median & IQR & z-value & 4.7 \\
\hline $\begin{array}{c}\text { Mean } \mathrm{ScvO}_{2} \\
(\mathrm{~mm} \mathrm{Hg})\end{array}$ & Nonsurvivors & 53.34 & 4.08 & 53 & -8.537 & $1.38 \mathrm{E}-17$ \\
\cline { 2 - 7 } & Survivors & 76.33 & 5.03 & 74.4 & 7.33 & Difference is significant \\
\hline
\end{tabular}

Table 2: The overall mean day 1 APACHE II score in patient who died was $24.47 \pm 4.49$ and the mean day 1 APACHE II score in patient who survived was $11.19 \pm 1.70$. This difference was statistically significant (Mann Whitney test, $p$-value $8.25 \mathrm{E}-18$ ). Thus mortality was associated with high mean APACHE II scores.

\begin{tabular}{|c|c|c|c|c|c|c|c|}
\hline Variable & Outcome & Mean & Std.deviation & Median & IQR & z-value & 6 \\
\hline \multirow{2}{*}{$\begin{array}{c}\text { D1-APACHE II } \\
\text { score }\end{array}$} & Nonsurvivors & 24.47 & 4.49 & 25 & -8.596 & $8.25 \mathrm{E}-18$ \\
\cline { 2 - 7 } & Survivors & 11.19 & 1.7 & 10 & 2 \\
\hline
\end{tabular}

Receiver operating characteristic (ROC) curve plotted for day 1 APACHE II score and Mean $\mathrm{ScvO}_{2}(\mathrm{~mm} \mathrm{Hg})$ by outcome (death) to get cutoff for these two variables. Figure $3 \& 4$ showed high sensitivity and specificity of day 1 APACHE II score in predicting outcome (death) if the score is $>14$.andif mean $\mathrm{ScvO}_{2} \leq 63.33$. Binary Logistic Regression was performed between Outcome as dependent variable and day 1 APACHE II score as well as mean $\mathrm{ScvO}_{2}(\mathrm{~mm} \mathrm{Hg})$ as independent (predictor) variables in cases. Day 1 APACHE II score as well as mean $\mathrm{ScvO}_{2}$ are not statistically significant predictors of outcome of death.

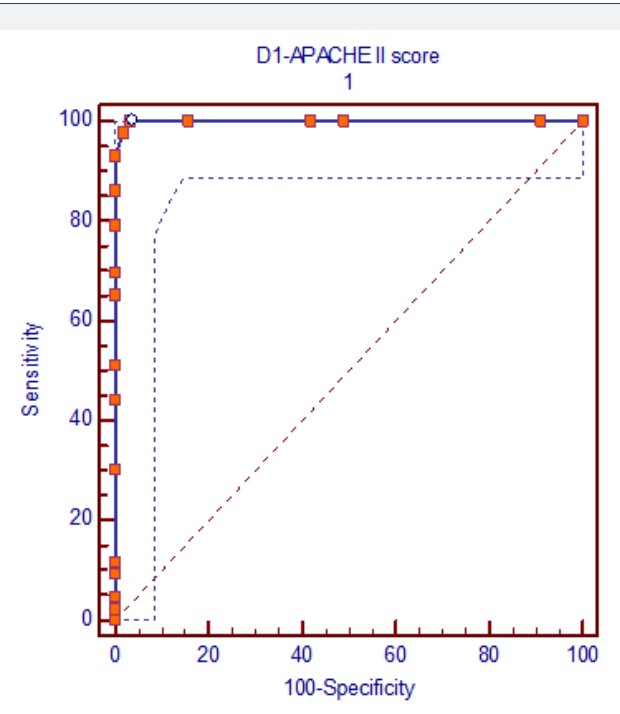

Figure 3: ROC for day 1 APACHE II. 
ventilator support for more than 24 hours. We are aware that $\mathrm{ScvO}_{2}$ is slightly lower than mixed venous oxygen saturation $\left(\mathrm{SvO}_{2}\right)$. This difference may be negated or reversed in shock patients [3]. However the presence of low $\mathrm{ScvO}_{2}$ most probably indicates a lower $\mathrm{SvO}_{2}$. In fact $\mathrm{ScvO}_{2}$ may overestimate $\mathrm{SvO}_{2}$. Ramkrishna et al. [9] showed that though there were some differences between $\mathrm{SvO}_{2}$ and $\mathrm{ScvO}_{2}$ depending on patients hemodynamics there was a fairly good correlation between them. As organ failure sets in conjunction with sepsis mortality increases and may approach nearly $80 \%$ when more than two organs fail. This can be reduced by individualized EGDT aimed at optimizing the oxygen delivery.

In clinical practice scoring systems have been used to evaluate the severity of disease process. APACHE II scoring system is a quantitative indicator of several patient characteristics, including vital signs and organ dysfunction, to assess severity of condition, evaluate prognosis or progression [7]. Thus it is a valuable tool to aid ICU clinicians in early diagnosis and helps them to initiate evidence-based protocols for critically ill patients. It also provides gross estimate of mortality risks in critically ill patients. Rivers et al conducted a study on EGDT in the treatment of severe sepsis and septic shock and concluded that EGDT provided at the earliest stages of severe sepsis and septic shock, has significant shortterm and long-term gains. However this was refuted by the ARISE trial which concluded that EGDT when compared with usual resuscitation practice did not decrease mortality in septic shock [10].

However the elements of EGDT have been endorsed by the surviving sepsis guidelines 2012 with $\mathrm{ScvO}_{2}$ target of $>70 \%$ been mentioned as one of the endpoints $[6,11]$. Walley put forward that similar physiologically targeted rapid resuscitation regimes are helpful in other shock states and concluded that it may result in successful patient management [6]. Thus the aim of the study was to observe the measured values of $\mathrm{ScvO}_{2}$ and their comparison with the outcome as measured by APACHE II score in critically ill patient treated by EGDT in 100 post operative and trauma patients.

EGDT was given to all patients in our post surgical care unit or trauma ward on admission as per a routine protocol. This protocol was adhered to achieve hemodynamic stability wherever possible. However despite this treatment, initial clinical comorbid conditions or the severity of trauma on admission resulted in patient mortality and our study aims to assess and evaluate hemodynamic parameters and role of $\mathrm{ScvO}_{2}$ in prediction of adverse outcome. $\mathrm{ScvO}_{2}$ was measured intermittently and compared with the outcome as measured by APACHE II score. APACHE II scoring was done only once on admission of patient. The clinical end point of study was survival (discharge from ICU) or death of the patient. We also observed that patients who received EGDT with $\mathrm{ScvO}_{2}$ up to $70 \%$, showed higher survival rate. Of the observed hemodynamic variables MAP, CVP, urine output and $\mathrm{PaO}_{2}$ were higher and $\mathrm{PaCO}_{2}$ lower in survivors than in nonsurvivors which was statistically significant.

\section{Correlation of outcome based on $\mathrm{ScvO}_{2}$ measurement and APACHE II}

APACHE II score as a predictor of mortality has been used in many studies in the literature. Our study also used APACHE II scoring system which was done on day 1 and came to the same results. The optimal day 1 APACHE II cutoff value for outcome (death) prediction was 14. Similar results were observed by Gupta et al. [8] who performed a study on evaluation of APACHE II score for an Indian patient with respiratory problems. Thus high APACHE II score is associated with high predictability of outcome (death). Our study used $\mathrm{ScvO}_{2}$ measurement as a predictor of mortality in critically ill patients admitted to post surgical unit or trauma ward. We observed consistent results where low $\mathrm{ScvO}_{2}$ was associated with higher mortality. For outcome prediction the optimal $\mathrm{ScvO}_{2}$ cutoff value was $\leq 63.33$. In a study by Perner et al. [12] they found that $\mathrm{ScvO}_{2}$ measurement of $\geq 64 \%$ indicated CITD $>2.5 \mathrm{l} / \mathrm{min} / \mathrm{m} 2$ in ICU patients with septic shock. Thus it can be used as an indirect measurement of cardiac output in absence of invasive cardiac output monitors.

We used binary Logistic Regression between Outcome as dependent variable and day 1 APACHE II score as well as Mean $\mathrm{ScvO}_{2}$ (mm Hg) Independent (Predictor) Variables in cases and came to the conclusion that day 1 APACHE II score as well as Mean $\mathrm{ScvO}_{2}$ are not statistically significant predictors of outcome. Bracht et al. [13] in his observational study showed that $\mathrm{ScvO}_{2}$ of less than $60 \%$ on unplanned admission to the ICU was associated with high mortality, but not with an increased length of stay in the hospital and this change in $\mathrm{ScvO}_{2}$ is not related to outcome [13]. As per the recent surviving sepsis guidelines though there are newer modalities of measuring cardiac output such as measuring the inferior vena cava size using bedside ultrasound or using the echocardiography or pulse pressure waveforms these may not be available to every patient in the early hours of resuscitation and during this period a low $\mathrm{SCVO}_{2}$ may provide a useful information which can be integrated in clinical practice $[14,15]$. Also compared to cardiac output measurements where there may be large errors with interpretations in cases of small errors in measurements, $\mathrm{SVO}_{2}$ or its surrogate $\mathrm{ScvO}_{2}$ is less likely to be erroneous in interpreting tissue oxygenation. It also recommend that to start resuscitation immediately when there is hypotension or elevated lactate above $4 \mathrm{mmol} / \mathrm{l}$ and to assess the adequacy of oxygen delivery using central venous oxygen saturation as one of the resuscitation goals. This study also states that the efficacy of EGDT has been proven in septic shock states and its value in other shock conditions needs further evaluation [16]. In our set up also where limited resources are available $\mathrm{ScvO}_{2}$ serves as an alternative tool to guide resuscitation. As these trauma victims and postoperative patients who were on ventilator, early sepsis could not be ruled out.

Thus we decided to conduct this study in our setting and we concluded that $\mathrm{SCVO}_{2}$ measurements can be used to target successful management in other scenarios like post operative 
and trauma patients. Limitations of our study was that we did not have continuous display of $\mathrm{ScvO}_{2}$ and we relied on intermittent measurements and since we did not have a pulmonary artery catheter placed in all patients we could not compare the $\mathrm{ScvO}_{2}$ with $\mathrm{SvO}_{2}$.

\section{Conclusion}

$\mathrm{ScvO}_{2}$ and day 1 APACHE II score both are highly sensitive and specific measures for predicting mortality in intensive care patients receiving early goal directed therapy. In our study the cut off value for prediction of mortality for day1 APACHE II score was 14 and for Mean $\mathrm{ScvO}_{2}$ it was 63.33. However mean $\mathrm{ScvO}_{2}$ measurement as well as day 1 APACHE II score are not statistically significant individual predictors of outcome.

\section{Financial Support and Sponsorship}

Nil.

\section{Conflicts of Interest}

There are no conflicts of interest.

\section{References}

1. Nebout S, Pirracchio R (2012) Should We Monitor $\mathrm{ScvO}_{2}$ in Critically ill Patients? Cardiology research and Practice. p. 1-7.

2. Rivers E, Nguyen B, Havstad S, Ressler J, Muzzin A, et al. (2001) Early goal-directed therapy in the treatment of severe sepsis and septic shock. N Engl J Med 345: 1368-1377.

3. Rivers EP, Ander DS, Powell D (2001) Central venous oxygen saturation monitoring in the critically ill patient. Curr Opin Crit Care 7(3): 204211.

4. Hartog C, Bloos F (2014) Venous oxygen saturation. Clin Anaesthesiol 28(4): 419-428.
5. Shalaby MA, Mahmoud M, Salama AM, Eweida TM, Salah M (2014) Central Venous Oxygen Saturation as a Predictor of the Outcome of Weaning From Mechanical Ventilation. Journal of Education and Practice 5(7): 175-182.

6. Walley KR (2011) Use of Central Venous Oxygen Saturation to Guide Therapy. Am J Respir Crit Care Med 184(5): 514-520.

7. Knaus WA, Draper EA, Wagner DP, Zimmerman JE (1985) APACHE II: a severity of disease classification system. Cril Care Med 13(10): 818829.

8. Gupta R, Arora VK (2004) Performance evaluation of APACHE II score for an Indian patient with respiratory problems. Indian J Med Res 119(6): 273-282.

9. Ramakrishna MN, Hegde DP, Kumarswamy GN, Gupta R, Girish TN (2006) Correlation of mixed venous and central venous oxygen saturation and its relation to cardiac index. Indian J Crit Care Medicine 10(4): 230-234

10. Peake SL, Delaney A, Bailey M, Bellomo R, Cameron PA (2014) GoalDirected Resuscitation for Patients with Early Septic Shock. N Engl J Med 371(16): 1496-1506.

11. Dellinger RP, Levy MM, Rhodes A (2013) Surviving Sepsis Campaign: Internationalguidelines for management of severe sepsis and septic shock: 2012. Critical Care Medicine 41(2): 580-637.

12. Perner A, Haase N, Wiis J, White JO, Delaney A (2010) Central venous oxygen saturation for the diagnosis of low cardiac output in septic shock patients. Acta Anaesthesiol Scand 54(1): 98-102.

13. Bracht H, Hänggi M (2007) Incidence of low central venous oxygen saturation during unplannedadmissionsin a multidisciplinary intensive care unit: an observational study. Crit Care 11(1): R2.

14. Statement from the Surviving Sepsis Campaign Leadership on CVP, $\mathrm{ScvO}_{2}$, and Lactate Measurements.

15. Updated Bundles in Response to New Evidence - Surviving Sepsis.

16. Ducrocq N, Kimmoun A, Levy B (2013) Lactate or $\mathrm{SCVO}_{2}$ as endpoints in resuscitation of shock states? Minerva Anestesiol 79(9): 1049-1058.

This work is licensed under Creative Commons Attribution 4.0 License DOI: 10.19080/JAICM.2018.06.555698

\section{Your next submission with Juniper Publishers will reach you the below assets}

- Quality Editorial service

- Swift Peer Review

- Reprints availability

- E-prints Service

- Manuscript Podcast for convenient understanding

- Global attainment for your research

- Manuscript accessibility in different formats

( Pdf, E-pub, Full Text, Audio)

- Unceasing customer service

Track the below URL for one-step submission https://juniperpublishers.com/online-submission.php 